\title{
Impacto potencial de mudanças climáticas sobre as necessidades de irrigação da cultura do milho no Rio Grande do Sul
}

\section{Bruno Collischonn José Antônio Louzada}

RESUMO: A cultura do milho representa uma parcela importante da produção agrícola do Rio Grande do Sul, sendo cultivada na maior parte na modalidade de sequeiro. Desta forma, sua produtividade é altamente influenciada pela quantidade de chuva ocorrida nos meses de verão, sendo que vários trabalhos apontam que o milho irrigado pode apresentar rendimentos muito superiores. Neste trabalho, propusemos um modelo simplificado de balanço hídrico no solo, de forma a avaliar as necessidades de irrigação em uma área experimental no município de Eldorado do Sul-RS. A este modelo foram acoplados os resultados de 20 modelos de circulaçáo global atmosfera-oceano (AOGCMs), de forma a avaliar o impacto de eventuais mudanças climáticas futuras sobre as necessidades de irrigação. Os resultados mostraram que o milho de sequeiro, que atualmente já tem produção restrita nesta área específica, deverá se tornar inviável no futuro. $\mathrm{O}$ balanço hídrico tende a ficar mais crítico, principalmente devido à maior evapotranspiração.

PALAVRAS-CHAVE: mudança climática, irrigação, milho
ABSTRACT: Corn crops represent an important share of agricultural outputs of Rio Grande do Sul, but only a small fraction of the cultivated area is under irrigation. This crop is very sensible to variability in rainfall, with yields varying significantly in presence of irrigation in some cases. In this work, we propose a simple soil water budget model, in order to account for irrigation requirements in a experimental site in Eldorado do Sul-RS. We coupled the results of 20 Atmosphere-Ocean Global Circulation Models (AOGCMS) to the model in order to assess the impact of climate change over irrigation requirements. Results show that corn cultivation without irrigation tends to become unviable in the future in this region. Water budget tend to become more critical, mostly because of a higher evapotranspiration

KEYWORDS: Impact of climate, irrigation, corn.

\section{INTRODUÇÃO}

Em anos recentes tem havido uma intensa discussão e um quase consense nos meios científicos de que a emissão de gases resultante da atividade antrópica tem causado e seguirá causando alteraçôes no clima do globo terrestre. A possibilidade foi reforçada pelo Quarto Relatório do Painel Intergovernamental de Mudanças Climáticas (IPCC) em 2007. Este grupo de especialistas e tomadores de decisão reuniu resultados de vários modelos de circulação geral Atmosfera-Oceano (AOGCMs), que consistem em ferramentas que buscam representar o comportamento do clima (principalmente precipitação e temperatura) até o fim deste século, considerando diferentes cenários de aumento de emissōes, fornecendo respostas discretizadas no tempo e no espaço.

A partir dos resultados dos modelos do IPCC, especialistas de diversas áreas têm se dedicado a ava- liar os efeitos das alterações climáticas preditas sobre os respectivos aspectos sócio-econômicos: nível dos oceanos (e conseqüente inundação de áreas costeiras) aumento de doenças como a malária, recursos hídricos, extinção de espécies, atividades econômicas como um todo.

No caso específico da agricultura, as mudanças preditas podem acarretar impactos muito diversos de acordo com a região do planeta: áreas que atualmente são demasiado frias para a atividade agrícola podem se tornar mais aptas. Áreas atualmente aptas para agricultura de sequeiro, em que são preditas diminuições da precipitação, podem vir a aumentar as necessidades de irrigação, com pressão sobre os recursos hídricos existentes, e vice-versa. Tendo em vista ainda a varibilidade dos solos, a diversidade de combinações que pode ser esperada é significativa. 
Diferentemente das regiōes mais ao norte do país, onde boa parte das culturas de milho, soja e feijão são irrigadas, o Estado do Rio Grande do Sul não adota agricultura irrigada, à exceção do cultivo do arroz. Em anos recentes estas culturas têm apresentado perdas recorrentes devido às estiagens prolongadas no período de primavera e verão, em que se dá o cultivo. Berlato e Fontana (2003) evidenciam como a produtividade da soja está correlacionada com a ocorrência de fenômenos El Niño, indicadores de precipitação acima da média. Este fato tem inclusive motivado a adoção de políticas de incentivo ao aumento do armazenamento de água e da irrigação, principalmente de parte do governo estadual.

O rendimento do milho, em especial, é muito sensível à ocorrência de precipitação abaixo do normal, tendo uma resposta bem superior na presença de irrigação. Machado (2008) propõe produtividades médias de $6000 \mathrm{~kg} /$ ha para o milho de sequeiro e $10.000 \mathrm{~kg} / \mathrm{ha}$ para o milho irrigado em Unaí/MG, uma diferença de 66\%. Bergamaschi et al. (2004) assinalam que a produtividade média do milho no estado do RS variou de $2.097 \mathrm{~kg} / \mathrm{ha}$ em 1995/1996, durante período de precipitação abaixo do normal, para $3.750 \mathrm{~kg} / \mathrm{ha}$ em 2002/2003. Desta forma, dado que a maior parte dos modelos prediz um aumento da temperatura em todo o globo, é possível que a cultura do milho se torne completamente inviável sem irrigação no RS. Por outro lado, o aumento da temperatura, combinado com um aumento substancial da precipitação, poderia levar a produtividades mais altas mesmo sem necessidade de irrigação.

Neste trabalho, foram examinadas as necessidades de irrigação de uma cultura hipotética de milho numa área de argissolo vermelho distrófico típico em Eldorado do Sul (RS), considerando o período de 1961 a 1990, através de um modelo simplificado de balanço hídrico no solo. Em seguida, foram usados resultados dos AOGCMs do IPCC para gerar séries sintéticas do fim do presente século, e repetimos as simulaçōes de balanço hídrico. Desta forma, foi obtida uma estimativa do impacto das mudanças climáticas preditas sobre a necessidade de irrigação desta cultura na região. Adicionalmente, são feitas considerações sobre os possíveis desdobramentos sobre os recursos hídricos.

Desta forma, este trabalho propõe a acoplagem de modelos de diferentes escalas: os modelos climáticos globais, com resolução não superior a $250 \mathrm{~km}$ e um modelo mais detalhado do fluxo de água no solo e planta. Salienta-se que os modelos climáticos citados carregam incertezas significativas, de forma que os resultados de seu acoplamento com outros modelos, conforme proposto aqui, devem ser analisados com muita cautela. Adicionalmente, Koutsoyiannis et al. (2008) chamam a atenção para as limitaçōes do downscaling de modelos climáticos para áreas relativamente pequenas em intervalos mensais. Desta forma, o objetivo visa a realizar um exercício de previsão de impactos climáticos sobre a irrigação, mas também, e principalmente, a propor uma forma de abordar o problema, e fazer algumas considerações sobre possíveis efeitos, consciente das limitações existentes em todas as etapas da análise.

\section{METODOLOGIA}

Na primeira parte deste trabalho, procurou-se reproduzir a condição atual de necessidades de água do cultivo de milho na estação experimental agronômica da Universidade Federal do Rio Grande do Sul em Eldorado do Sul-RS. O local foi escolhido por dispor dos dados de solo necessários para a simulação em modelos detalhados de balanço hídrico. O período de 1961 a 1990 foi simulado com séries reais de precipitação e temperatura com o modelo que representa o fluxo de água no solo, descrito mais adiante. Ao fim da simulação, o número de intervalos de tempo com déficit hídrico foi contabilizado, obtendo-se uma estimativa do risco a que um produtor hipotético de milho na região esteve sujeito no período. Este cenário foi denominado cenário atual.

Em seguida, as séries de temperatura e precipitação foram modificadas, a partir dos resultados da média dos modelos extraída da plataforma MAGICC/ SCENGEN (descrita adiante). Os resultados deste modelo são dados em variação porcentual (no caso da precipitação) e em variação absoluta em ${ }^{\circ} \mathrm{C}$ (no caso da temperatura). O MAGICC/SCENGEN fornece a variação média para cada mês do ano. As séries diárias de 1961 a 1990 foram então modificadas considerando a variação mensal predita para o período de 20 anos centrado em 2090. Geraram-se, assim, séries sintéticas de precipitação e temperatura, cujas estatísticas tendem a ser similares às do clima predito para o fim do século.

De posse destas séries sintéticas, o modelo de água no solo foi novamente aplicado, mantendo-se as características de solo e demais variáveis, gerando assim o chamado cenário futuro. As necessidades de irrigação foram então comparadas. 


\section{Dados de solo}

Os dados de solo foram obtidos do trabalho de Martorano (2007). Segundo este trabalho, a tipologia do solo na estação experimental de Eldorado do Sul consiste em um argissolo vermelho distrófico típico, com $53 \%$ de areia, $29 \%$ de silte e $18 \%$ de argila. Dalmago (2004) ajustou a equação de Van-Genuchten aos dados experimentais obtidos na área experimental. A equação de Van Genuchten é:

$$
\theta_{a}=\theta_{r}+\frac{\theta_{s}-\theta_{r}}{\left[1+\left(\alpha\left|\psi_{m}\right|\right)^{n}\right]^{m}}
$$

Onde:

$\theta_{\mathrm{a}}=$ umidade atual (-);

$\theta_{\mathrm{r}}=$ umidade residual $(-)$;

$\theta_{s}=$ umidade de saturaçáo do solo (-)

$\Psi_{\mathrm{m}}=$ potencial matricial $(\mathrm{MPa})$;

$\alpha\left(\mathrm{MPa}^{-1}\right), \mathrm{m}, \mathbf{n}=$ parâmetros da equação de Van Genuchten;

A Tabela 1 mostra os parâmetros de Van Genuchten obtidos por Dalmago (2004) para a área experimental, sob plantio direto, de acordo com a profundidade.

TABELA 1

Parâmetros da equação de Van Genuchten no solo da estação experimental de Eldorado do Sul, para milho sob plantio direto

\begin{tabular}{c|c|c|c|c|c}
\hline Prof. & $\mathbf{a}$ & $\mathbf{m}$ & $\mathbf{n}$ & $\theta \mathbf{r}$ & $\theta \mathbf{s}$ \\
\hline $7,5 \mathrm{~cm}$ & 211 & 0,4073 & 1,6873 & 0,14 & 0,35 \\
\hline $15 \mathrm{~cm}$ & 493 & 0,3683 & 1,5830 & 0,16 & 0,35 \\
\hline $30 \mathrm{~cm}$ & 410 & 0,3285 & 1,4826 & 0,17 & 0,36 \\
\hline $45 \mathrm{~cm}$ & 184 & 0,5408 & 2,1778 & 0,147 & 0,40 \\
\hline $60 \mathrm{~cm}$ & 384 & 0,453 & 1,8283 & 0,20 & 0,40 \\
\hline
\end{tabular}

\section{Dados da cultura do milho}

O trabalho de Manfron et al. (2003) apresenta valores médios para a profundidade do sistema radicular do milho, de acordo com o número de dias após a semeadura. A estes valores foi ajustado um polinômio relacionando estas duas variáveis, para fins de simulação. A Figura 1 mostra o ajuste polinomial efetuado.

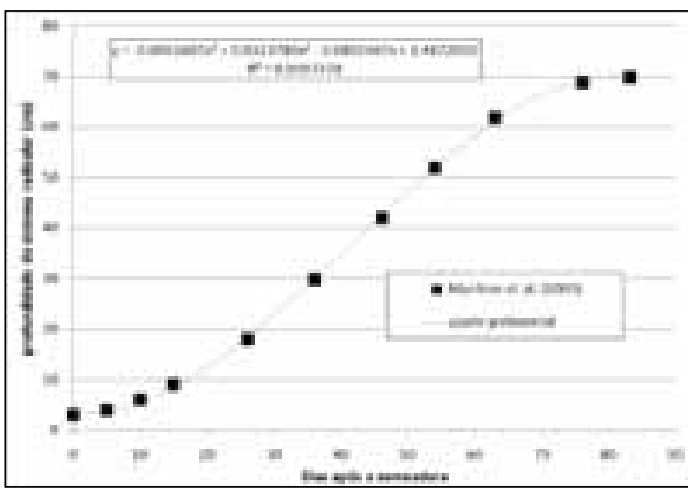

FIGURA 1. Ajuste polinomial à variação da profundidade do sistema radicular, proposta por Manfron et al (2003).

Guerra e Jacomazzi (2001) apresentam dados tabelados do coeficiente de cultura (Kc) do milho, de acordo com o número de dias após o plantio. No presente trabalho, propõe-se que a simulação do cultivo do milho se inicie em 21 de outubro e tenha um ciclo de 100 dias. Baseado na tabela de Guerra e Jacomazzi (2001) foi ajustado um polinômio à variação do coeficiente de cultura do milho, de acordo com o período de cultivo. O polinômio ajustado é mostrado na Figura 2.

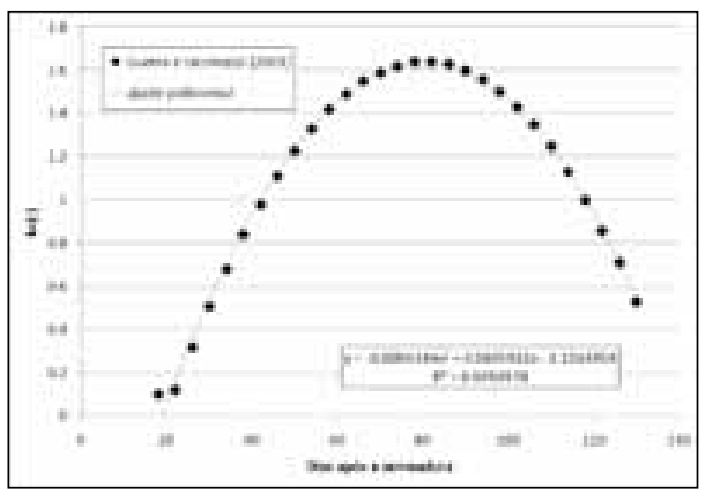

FIGURA 2. Ajuste polinomial à variação do coeficiente de cultura do milho, proposta por Guerra e Jacomazzi (2001) 


\section{Dados de Precipitação}

A série de precipitaçôes diárias foi obtida da estação pluviométrica Guaíba Country Club (03051005) disponível no banco de dados da Agência Nacional de Águas (ANA) e bastante próxima ao local da Estação Experimental. Em períodos com falhas, as séries foram preenchidas com dados das estações pluviométricas Butiá (03051031), Charqueadas (02951067) e Triunfo (02951032).

Foi gerada uma série de precipitações diárias de 1961 a 1990, para coincidir com o período de base da maior parte dos modelos de circulação global.

\section{Evapotranspiração}

Para estimativa da evapotranspiração no cenário atual e futuro, foi utilizado o método de Penman-Monteith, conforme sintetizado em Collischonn (2001).

Como dados de entrada, foram utilizadas as normais climatológicas do INMET da estação Encruzilhada do Sul, das seguintes variáveis, necessárias à utilização do método de Penman-Monteith: temperatura média do ar, umidade relativa do ar, pressão atmosférica, insolação e velocidade do vento.

O cálculo da evapotranspiração de referência foi feito adotando-se um albedo de 0,23 e uma altura média da vegetação de $0,12 \mathrm{~m}$. A evapotranspiração do milho em seus diversos estágios foi calculada através da multiplicação pelo coeficiente de cultivo correspondente.

Para cálculo da evapotranspiração no cenário futuro, foram utilizadas as temperaturas modificadas, obtidas da soma das normais de temperatura à variação predita pelos modelos do IPCC. As demais variáveis climáticas foram mantidas constantes no cenário futuro, uma vez que os modelos não fornecem resultados sobre sua variabilidade.

\section{Modelo de necessidades hídricas}

O modelo de necessidades hídricas é baseado no conceito de capacidade de água disponível (CAD). $\mathrm{O} C A D$ em mm é dado por:

$$
C A D=(C-P M P) \cdot Z
$$

Onde CC é a umidade correspondente à capacidade de campo, PMP é a umidade no ponto de murcha permanente e $Z$ é a profundidade do sistema radicular, em $\mathrm{mm}$.

A umidade correspondente à capacidade de campo e ao ponto de murcha permanente são obtidas através da equação de Van Genuchten, considerando que a tensão em capacidade de campo é de $100 \mathrm{cca}$ ou 0,01 $\mathrm{MPa}$ e que a tensão no ponto de murcha permanente é de $15.000 \mathrm{cca}$ ou $1,47 \mathrm{MPa}$.

A precipitação efetiva, em cada dia, é calculada por separação do escoamento, através da seguinte equação:

$$
P_{e f}(i)=P(i)-Q(i)
$$

Onde $\mathrm{P}(\mathrm{i})$ é a lâmina precipitada medida no intervalo de tempo i e $\mathrm{Q}(\mathrm{i})$ é o escoamento superficial, calculado pelo método do Soil Conservation Service (Tucci, 1993):

$$
Q(i)=\frac{(P(i)-0,2 \cdot S)^{2}}{P(i)+0,8 \cdot S}
$$

Em que $S$ é dado por:

$$
S=\frac{25400}{C N}-254
$$

O coeficiente CN é tabelado. Sartori et al. (2005) propõem que os argissolos em geral sejam incluídos entre os solos de classe $\mathrm{C}$, que possuem baixa taxa de infiltração. Considerando uma cobertura de plantação de cereais, em curvas de nível, o valor tabelado para o coeficiente $\mathrm{CN}$ é de 82 .

O balanço hídrico do solo é calculado por:

$$
\mathrm{St}(\mathrm{i})=\mathrm{St}(\mathrm{i}-1)+\mathrm{P}_{\text {ef }}(\mathrm{i})-\mathrm{Etc}(\mathrm{i})
$$

Onde Etc(i) é a evapotranspiração do milho no intervalo de tempo, dada por:

$$
\operatorname{Etc}(i)=\operatorname{Etr}(i) \cdot k c
$$

Caso o armazenamento seja superior ao CAD, há percolaçáo por gravidade, ou seja:

$$
\begin{gathered}
\operatorname{Perc}(i)=S(i)-C A D \text {, se } S t(i)>C A D \\
\operatorname{Perc}(i)=0, \text { se } \operatorname{St}(i) \leq C A D
\end{gathered}
$$


Quando o armazenamento de água no solo resulta inferior a um determinado limite, há necessidade de irrigação. $\mathrm{O}$ limite é dado pelo fator $\mathrm{f}$, que expressa a parcela da água no solo disponível pra uso da planta sem perda de produtividade. $\mathrm{O}$ valor recomendado para grãos é de 0,4 a 0,6. Sendo assim, adota-se um fator $\mathrm{f}$ de 0,5 , o que significa que há necessidade de irrigação sempre que o armazenamento for inferior a $50 \%$ da CAD. Sendo assim, a necessidade de irrigação é dada por:

$$
\begin{gathered}
\operatorname{Irr}(\mathrm{i})=0, \text { se } \mathrm{St}(\mathrm{i})>0,5 \cdot \mathrm{CAD} \\
\operatorname{Irr}(\mathrm{i})=0,5 \cdot \mathrm{CAD}-\mathrm{S}(\mathrm{i}) \text {, se } \mathrm{St}(\mathrm{i})<0,5 \cdot \mathrm{CAD}
\end{gathered}
$$

Neste segundo caso, o armazenamento é ainda corrigido para levar em conta a lâmina irrigada, ou seja:

$$
\operatorname{St}(\mathrm{i})=\operatorname{St}(\mathrm{i})+\operatorname{Irr}(\mathrm{i}) \text {; }
$$

A adoção de um fator de irrigação mais alto, além de ser recomendado para culturas de menor valor agregado como o milho, permite uma maior flexibilização do manejo da irrigação, dado que o produtor pode acionar o sistema de irrigação com menor freqüência, na expectativa de que precipitações ocorram. Este manejo é interessante no RS, em que as estações de chuva e seca não são bem definidas, podendo ocorrer precipitaçôes mesmo no período de verão.

\section{Mudanças climáticas: MAGICC/SCENGEN}

Para a consideração das mudanças climáticas na análise realizada, foram obtidos os resultados de 20 modelos de circulação Atmosfera-Oceano (AOGCMs), compilados no ambiente MAGICC/ SCENGEN, que é um software amigável focado na disponibilização de cenários de mudança climática para especialistas e não-especialistas (Hulme et al. 2000). MAGICC/SCENGEN fornece a mudança da precipitação média (relativa à média do período de 20 anos centrado em 1990), bem como a variação absoluta da temperatura, em grades de $2,5^{\circ} \times 2,5^{\circ}$, para o período de 20 anos centrado em qualquer ano até 2100 . Trata-se de uma compilação do Projeto

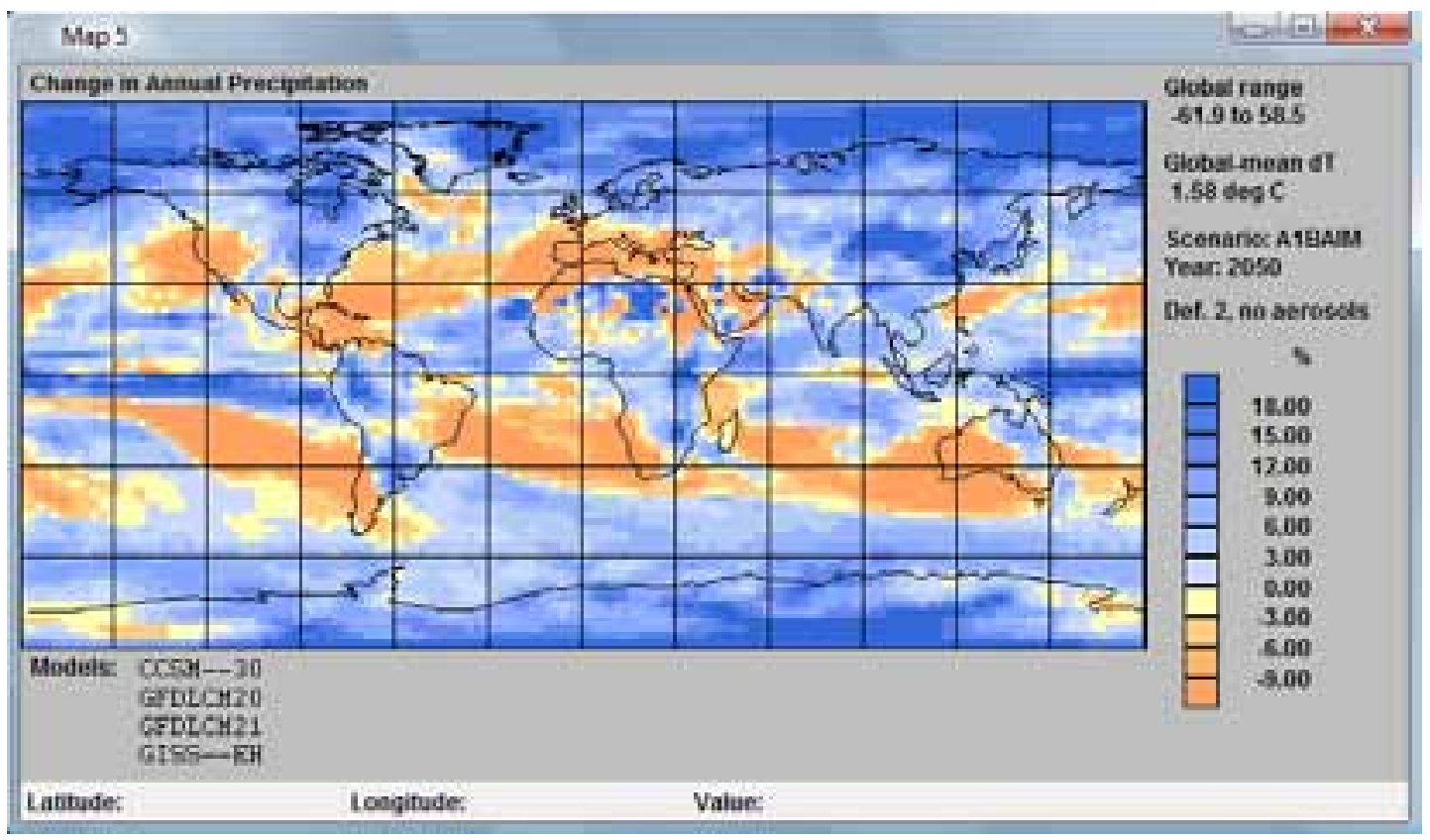

FIGURA 3. Exemplo de resultados do ambiente MAGICC/SCENGEN: variação na precipitação média no clima em $2050 \mathrm{em}$ todo o globo (pixels em cores mais quentes indicam diminuição da chuva). 
de Intecomparação de Modelos Acoplados, fase 3 (CMIP3), que é considerado o maior e mais abrangente experimento internacional de acoplagem de modelos climáticos já realizado (Meehl et al. 2007). No ambiente MAGICC/SCENGEN, estes resultados podem ser obtidos para cada modelo (AOGCM) ou para a média dos modelos. Os resultados dependem ainda do cenário de emissões considerado: cenário tendencial (A2BAIM) ou cenário com políticas de restrição de emissões de CO2 (B2AIM), tais como o Protocolo de Kyoto. A Figura 3 mostra um exemplo dos dados de mudança climática armazenados no ambiente MAGICC/SCENGEN. Para este trabalho, foram obtidas as variaçōes preditas sobre o pixel limitado pelas coordenadas $30^{\circ} \mathrm{S}$ e $32,5 \mathrm{~S}$ e $50^{\circ} \mathrm{W}$ e $52,5^{\circ} \mathrm{W}$, que engloba a área da Estação Experimental.

\section{RESULTADOS}

\section{Simulação no cenário atual}

Conforme mencionado, o modelo de necessidades hídricas foi simulado em intervalo diário, no período de 1961 a 1990, com especial interesse no período de 21 de outubro a 29 de janeiro, período adotado para o cultivo de milho.

A Erro! Fonte de referência não encontrada. mostra as médias das principais grandezas resultantes do modelo, durante o período de cultivo, em $\mathrm{mm}$ : precipitação $(\mathrm{P})$, escoamento superficial $(\mathrm{Q})$, infiltração (I), evapotranspiração (E), necessidade de irrigação (Irr), percolação (Perc) e variação do armazenamento $(\Delta S)$.

\section{TABELA 2}

Média das variáveis de estado do modelo de necessidades hídricas (mm), 1961-1990

\begin{tabular}{c|c|c|c|c|c|c}
\hline $\mathbf{P}$ & $\mathbf{Q}$ & $\mathbf{I}$ & $\mathbf{E}$ & Irr & Perc & $\Delta \mathbf{S}$ \\
\hline 310 & 39 & 272 & 404 & 262 & 99 & 30 \\
\hline
\end{tabular}

Como se vê, a precipitação efetiva não é suficiente para suprir a demanda de evapotranspiração do milho, resultando em uma necessidade média de irrigação de $262 \mathrm{~mm}$ por cultivo de 100 dias, ou 2,6 mm/dia.

A necessidade de irrigação apresentou uma variabilidade entre as diversas safras simuladas. Na Tabela 3, são mostradas as necessidades médias diárias de irrigação obtidas nas 29 safras simuladas. Além disso, a tabela mostra se houve um evento significativo de El Niño (EN, chuva acima do normal do RS) ou La Niña (LN, chuva abaixo do normal), conforme Berlato e Fontana (2003).

Como se vê, o modelo de necessidades de irrigação apresentou alguma coerência com a ocorrência de eventos que causam anomalias de precipitação no RS. Nos períodos de El Niño de 1965/1966 1982/1983, a necessidade hídrica diária média foi mais baixa, enquanto nos eventos La Niña de 1973/1974, o modelo calculou uma necessidade de irrigação de $3,5 \mathrm{~mm} /$ dia em média, uma das mais altas. Na safra de 1987/1988, embora não tenha ocorrido La Niña, houve uma estiagem que causou fortes prejuízos às lavouras de milho e soja no RS. Neste período, a necessidade de irrigação teria sido acima da média (3,3 $\mathrm{mm} /$ dia em média).

TABELA 3

Necessidades de irrigação médias diárias simuladas nas 29 safras de 1961 a 1990, em mm, e indicação de ocorrência de eventos El Niño (EN) ou La Niña (LN)

\begin{tabular}{l|c|c|c|c|c}
\hline Safra & Irr & evento & Safra & Irr & evento \\
\hline $61 / 62$ & 2,3 & & $76 / 77$ & 2,1 & \\
\hline $62 / 63$ & 2,8 & & $77 / 78$ & 2,4 & \\
\hline $63 / 64$ & 3,3 & & $78 / 79$ & 2,9 & \\
\hline $64 / 65$ & 2,8 & & $79 / 80$ & 2,6 & \\
\hline $65 / 66$ & 1,9 & EN & $80 / 81$ & 2,4 & \\
\hline $66 / 67$ & 1,8 & & $81 / 82$ & 3,0 & \\
\hline $67 / 68$ & 3,3 & & $82 / 83$ & 2,4 & EN \\
\hline $68 / 69$ & 2,3 & & $83 / 84$ & 2,5 & \\
\hline $69 / 70$ & 3,1 & & $84 / 85$ & 2,8 & \\
\hline $70 / 71$ & 2,1 & & $85 / 86$ & 3,3 & \\
\hline $71 / 72$ & 1,7 & & $86 / 87$ & 2,6 & \\
\hline $72 / 73$ & 2,8 & EN & $87 / 88$ & 3,3 & \\
\hline $73 / 74$ & 3,5 & LN & $88 / 89$ & 2,6 & LN \\
\hline $74 / 75$ & 2,6 & & $89 / 90$ & 2,2 & \\
\hline $75 / 76$ & 2,6 & LN & & & \\
\hline
\end{tabular}

De forma geral, no entanto, o que chama atenção é que em todos os anos, mesmo naqueles com ocorrência de chuvas acima da média, houve necessidades de irrigação suplementar na cultura do milho. De fato, Berlato e Fontana (2003) afirmam que a precipitação 
pluvial normal de final de primavera e verão no RS é, em geral, insuficiente para atender as necessidades hídricas das culturas de soja e milho, limitando seus rendimentos.

\section{Variação climática predita}

De uma forma geral, as mudanças preditas para o Brasil são bastante difundidas, e dão conta de um aumento da precipitação no sul e uma diminuição no nordeste do país, em termos anuais. No entanto, para aplicaçôes como a proposta aqui, é importante uma idéia da variação intra-anual dos parâmetros climáticos, em função dos períodos de cultivo do milho.
Desta forma, foram obtidos dados da variação prevista para cada mês do ano da temperatura e precipitação médias no período de 2090 a 2110 , em relação ao período de 1980 a 2000 . Foram obtidas as variações preditas sobre o pixel definido pelas latitudes $30^{\circ} \mathrm{S} / 32,5^{\circ} \mathrm{S}$ e $50^{\circ} \mathrm{W} / 52,5^{\circ} \mathrm{W}$, que engloba a área da estação experimental agronômica da UFRGS em Eldorado do Sul-RS. Estes resultados dizem respeito à média de 20 modelos (AOGCMs) incluídos no CMIP3 e compilados no ambiente MAGICC/ SCENGEN. A Figura 4 mostra os resultados da previsão de aumento da temperatura para os 20 anos centrados em 2100. Já a Figura 5 mostra a variação prevista da precipitação no mesmo período.
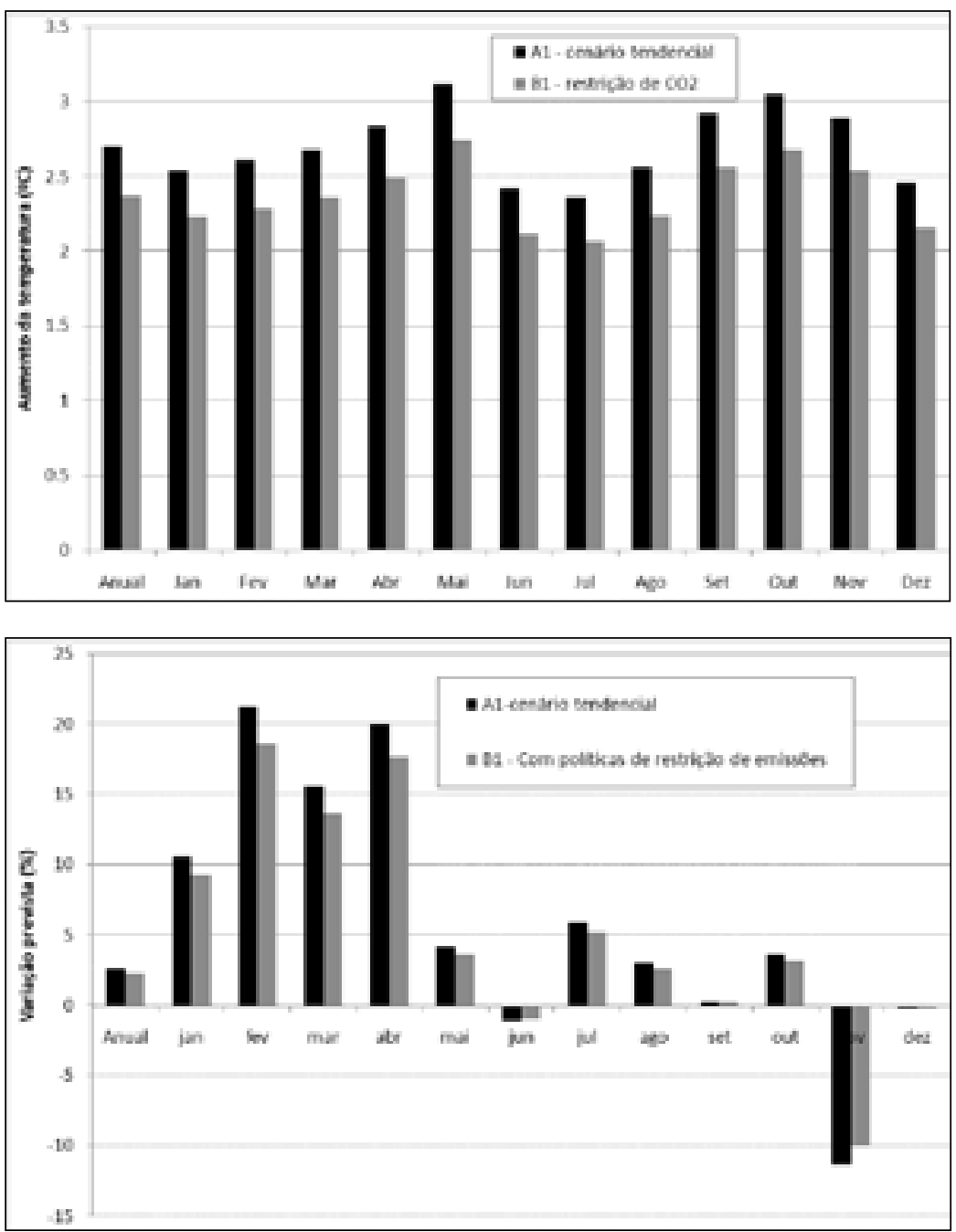

FIGURA 4. Variação prevista da temperatura no período de 2090 a 2110 em relação a 1980-2000, na região de Eldorado do Sul, média de 20 AOGCMs.
FIGURA 5. Variação porcentual prevista da precipitação no período de 2090 a 2110 em relação a 1980-2000, na região de Eldorado do Sul, média de 20 AOGCMs. 
Em primeiro lugar, vê-se que a média dos modelos prevê aumento da temperatura média em Eldorado do Sul em todos os meses do ano. O aumento tende a ser menor nos meses de inverno, no entanto será superior a $2^{\circ} \mathrm{C}$ mesmo na hipótese de restrições à emissão de carbono entrare em funcionamento efetivo. Aumentos superiores a $3^{\circ} \mathrm{C}$ em relação à média de alguns meses de outono e primavera são preditos.

Com relação à chuva, observa-se que, em média, está prevista uma variação positiva da precipitação na região de Eldorado do Sul no fim do presente século, em termos anuais. Pode-se perceber também que esta variação será menor se políticas de restrição de emissões de carbono forem eficazes.

Em termos sazonais, observa-se que o aumento previsto é mais intenso nos meses de janeiro a abril, correspondente a boa parte do verão e início do outono. No inverno e primavera, os AOGCMs prevêem pouca variação, à exceção do mês de novembro, em que uma redução importante da chuva é prevista.

Preliminarmente, pode-se constatar que, embora haja uma tendência prevista de aumento da precipitação como um todo na região, do ponto de vista do milho, possivelmente as necessidades de irrigação devem aumentar, uma vez que o período crítico da cultura (florescimento) corresponde aos meses de novembro e principalmente dezembro, quando uma diminuição da chuva é predita. Por outro lado, podem-se esperar rendimentos melhores do chamado "milho do tarde", com semeadura posterior ao convencional, com florescimento no mês de janeiro.

Além de verificar a variação predita pela média dos modelos, buscou-se observar como as previsões variavam de um modelo para outro. Previsões muito diversas entre os vários modelos podem indicar uma maior incerteza nas previsōes, e portanto uma menor confiabilidade nos impactos a serem avaliados neste trabalho. Desta forma a Figura 6 mostra a variabilidade entre as previsões de aumento de temperatura dos 20 AOGCMs, através de box-plots. Já a Figura 7 mostra a variabilidade das previsões de variação de precipitação.

Os gráficos mostram diferenças importantes nas respostas relativas às duas variáveis climáticas analisadas. Do ponto de vista da temperatura, é quase consenso entre os modelos climáticos de que haverá um aquecimento da região de Eldorado do Sul ao fim do século. Apenas nos meses de junho e julho uma minoria dos modelos prevê diminuição da temperatura média. Foram feitos testes de hipóteses de Student, cuja hipótese nula é de que a média dos aumentos de temperatura preditos pelos 20 AOGCMS é igual a zero. A um nível de significância de $5 \%$, a hipótese nula foi rejeitada para todos os meses, de forma que o aumento predito na temperatura pode ser considerado não-nulo.

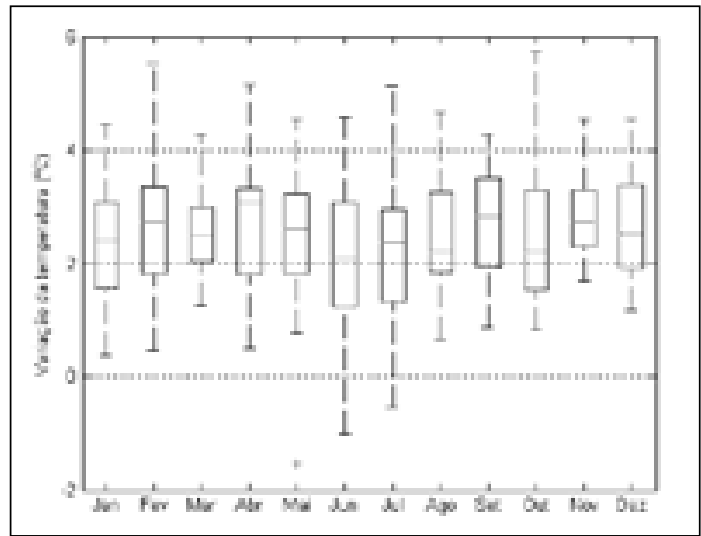

FIGURA 6. Variabilidade das previsões de aumento da temperatura entre os 20 AOGCMs.

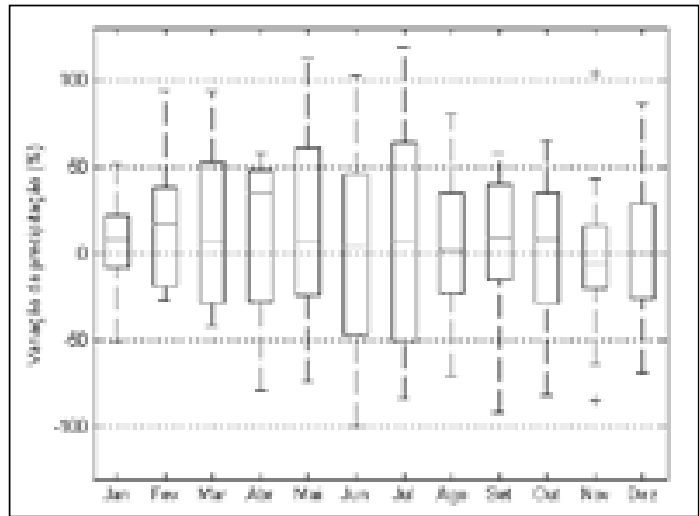

FIGURA 7. Variabilidade das previsões de variação de chuva entre 20 AOGCMs.

Já para a precipitação, as respostas são muito variadas. Embora as médias predigam aumento, vários modelos divergem. Também neste caso, foi feito um teste de hipótese de Student, no qual a hipótese nula foi de que a média das variaçôes percentuais preditas pelos 20 AOGCMs é igual a zero. Neste 
caso, diferentemente da temperatura, o teste não pôde rejeitar a hipótese nula para nenhum dos meses, nem tampouco para a média anual. A julgar pelos resultados dos modelos do IPCC, portanto, não é possível julgar se a precipitação na regiāo de estudo vai aumentar ou diminuir.

Cabe salientar que a Figura 6 e a Figura 7 mostram resultados do cenário tendencial. Para o cenário com restrições, o aspecto é similar, apenas com uma variabilidade menor.

\section{Simulação no cenário futuro e comparação entre os cenários}

O modelo de necessidades hídricas foi novamente simulado, considerando-se as novas séries de precipitação e evapotranspiração, obtidas dos prognósticos do SCENGEN. No caso da evapotranspiração, o método de Penman-Monteith foi utilizado adotando-se as temperaturas médias futuras preditas, ou seja, a Normal do INMET em cada mês, acrescida do aumento de temperatura médio predito. Já no caso da precipitação, adotou-se a mesma série do cenário de base (1961-1990), uma vez que os testes estatísticos não foram conclusivos no sentido de indicar aumento ou diminuição da chuva média em cada mês.

A Erro! Fonte de referência não encontrada. mostra o resultado médio das variáveis do balanço hídrico médio durante as 29 safras simuladas: Precipitação (P), Escoamento superficial (Q), Evapotranspiração (E), necessidade de irrigação (IRR), Percolação (Perc) e variação no armazenamento $(\Delta S)$.

TABELA 4

Comparação entre resultados do balanço hídrico médio do modelo, nos cenários atual e futuro, em $\mathrm{mm}$

\begin{tabular}{|c|c|c|c|c|c|c|}
\hline Cenário & P & Q & E & Irr & Perc & $\Delta S$ \\
\hline Atual & 310 & 39 & 404 & 262 & 99 & 30 \\
\hline Futuro & 310 & 39 & 450 & 295 & 94 & 22 \\
\hline
\end{tabular}

Como se vê, a evapotranspiração aumentou em cerca de $12 \%$, resultado do aumento da temperatura predito para todos os meses pela grande maioria dos modelos no RS. A conseqüência é que as necessidades de irrigação aumentaram praticamente na mesma proporção.
Os resultados sugerem que o cultivo de milho em sequeiro na região de Eldorado do Sul, que atualmente já é pouco difundido, deverá se tornar ainda mais inviável caso os prognósticos de mudanças climáticas se confirmem.

As simulaçôes foram repetidas considerando-se os prognósticos do cenário $\mathrm{B} 1$, que leva em conta um futuro com restriçōes de emissōes de carbono. Neste cenário, houve pouca alteração, sendo que as necessidades de irrigação aumentam em 10\%. Como se vê, o cenário de restrição de emissões teria pouco efeito na redução do déficit hídrico da cultura do milho, uma vez que no cenário tendencial as simulações estimaram um aumento de $12 \%$ nas necessidades de irrigação.

Por fim, as simulaçôes de necessidades de irrigação foram repetidas considerando os prognósticos dos 20 AOGCMS individualmente, de forma a verificar a variabilidade dos prognósticos. Neste caso, o aumento ou diminuição da precipitação, predito por cada modelo individual, foi levado em conta, aumentando-se a lâmina precipitada diária na proporção média predita pelo modelo para o mês em questão. A Figura 8 mostra os box-plots dos resultados das necessidades de irrigação considerando os prognósticos de 20 AOG$\mathrm{CMs}$, levando em conta ainda os cenários tendencial (A1) e de redução de emissões (B1).

Em termos da variação percentual, os resultados são mostrados na Figura 9.

Observa-se que, embora as simulações com os resultados de alguns AOGCMs resultem em uma diminuição das necessidades de irrigação, a maior parte dos modelos prevê mudanças no clima que acarretarão um aumento das necessidades de irrigação para a cultura do milho em Eldorado do Sul. Este cenário não deve se alterar muito mesmo no caso de eventuais políticas de redução de emissões terem sucesso nos próximos anos.

Salientam-se as grandes incertezas inerentes aos resultados dos modelos.

\section{CONCLUSÕES}

Neste trabalho, procurou-se analisar como as mudanças climáticas supostamente em curso podem afetar as necessidades de irrigação da cultura do milho na região de Eldorado do Sul-RS.

Em primeiro lugar, as simulaçōes mostraram que, no cenário atual, representado pelo clima no período de 1961-1990, já existe um déficit hídrico importante 


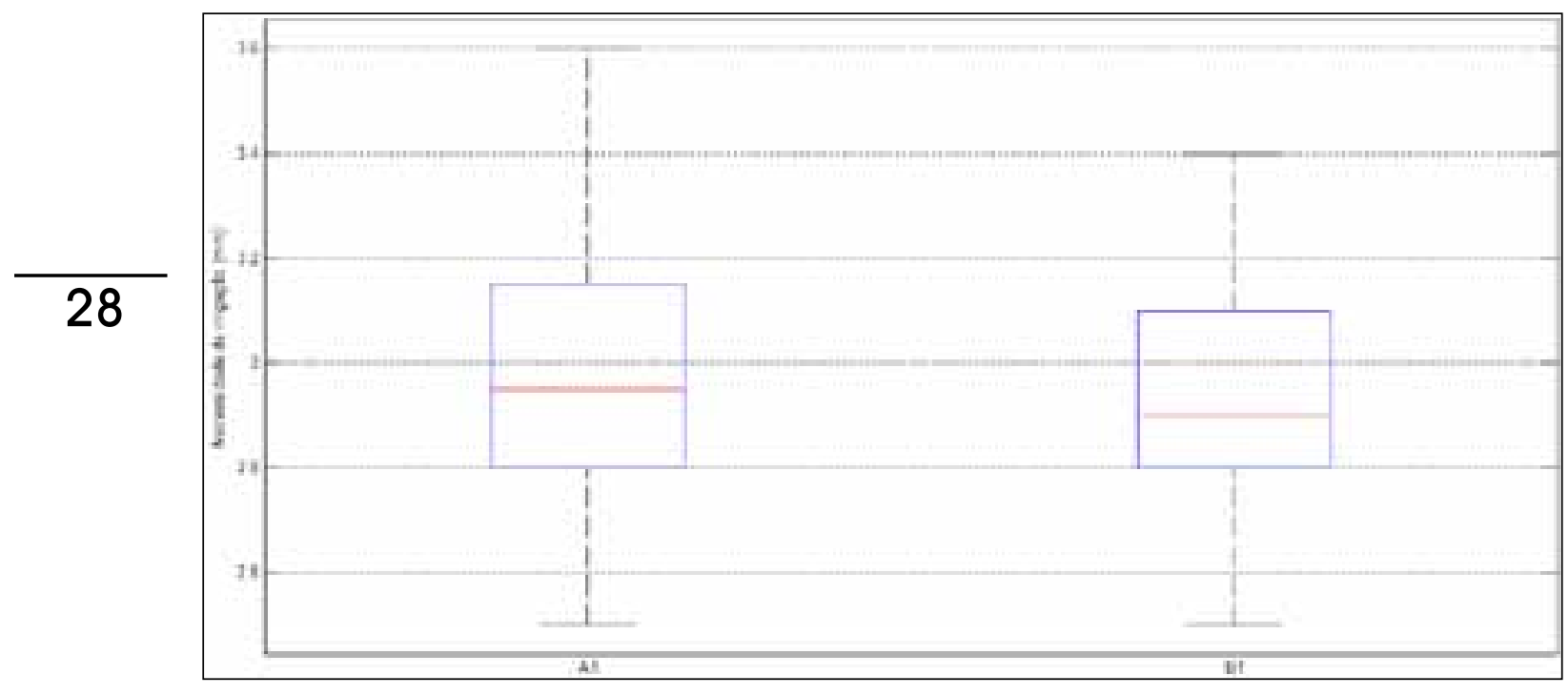

Figura 8. Variabilidade das necessidades de irrigação dos resultados usando os prognósticos dos 20 AOGCMs, considerando o cenário tendencial (A1) e de redução de emissões (B1).

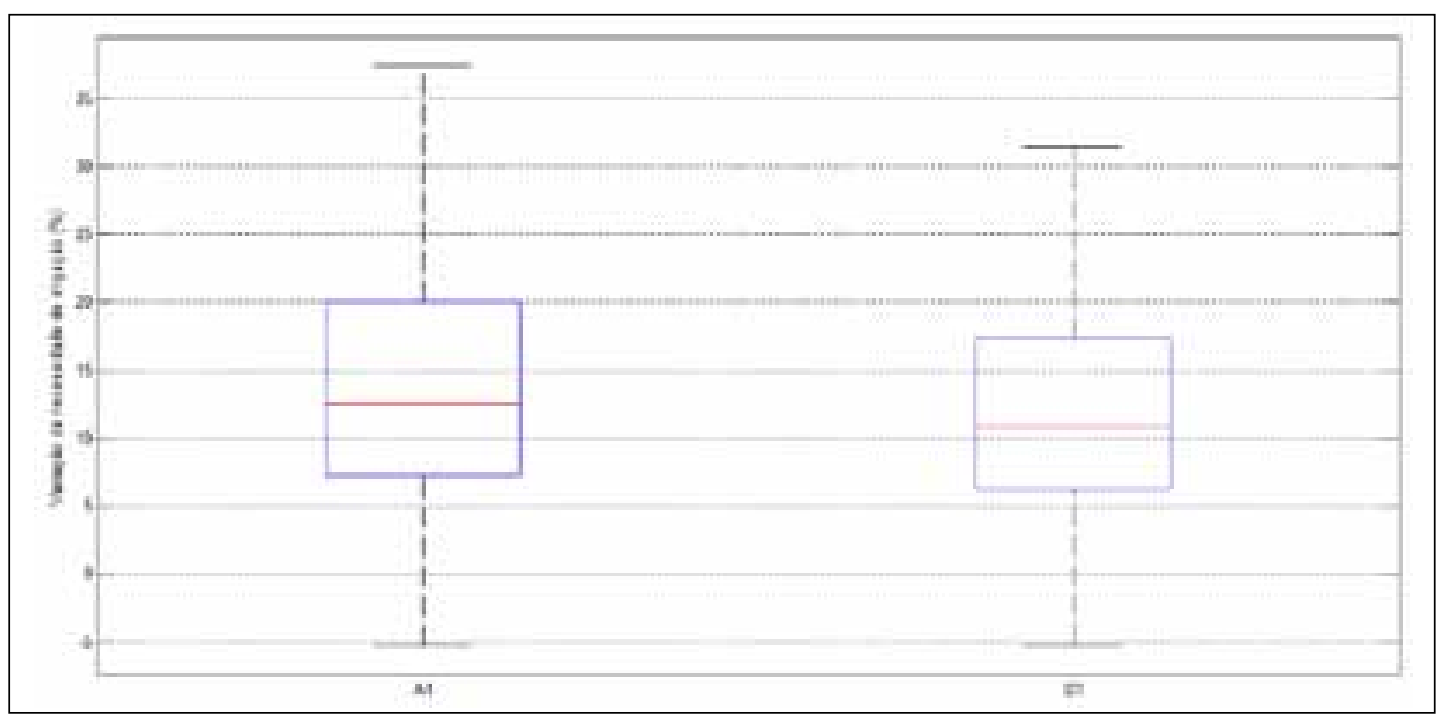

Figura 9. Variação porcentual da necessidade de irrigação em relação ao cenário atual, resultados de 20 AOGCMs considerando os cenários A1 e B1. 
na cultura do milho, sinalizando para uma necessidade de irrigação mesmo que o clima não se altere.

No cenário futuro, os resultados dos modelos de clima, acoplados com o modelo de necessidades de irrigação, mostraram que esta demanda se acentuará, provavelmente inviabilizando a cultura de milho de sequeiro nesta região do RS. O aumento do déficit hídrico se dará principalmente pelo aumento da evapotranspiração média, enquanto que a precipitação média ao longo do período de cultivo tende a não se alterar.

Deve-se salientar que a região de Eldorado do Sul não é uma tradicional produtora de milho atualmente, em parte provavelmente pelo déficit hídrico sinalizado neste trabalho no cenário atual. Sendo assim, entende-se que seria de interesse replicar este trabalho nas regiōes produtoras, em especial o planalto gaúcho. Como nesta região a precipitação anual é um pouco mais alta, o milho de sequeiro tende a ser mais viável atualmente, de forma que eventuais mudanças climáticas podem ter maior impacto nesta região. $\mathrm{O}$ mesmo vale para outras culturas de importância para o RS, tal como a soja e, eventualmente, o arroz.

Salientam-se as grandes incertezas inerentes aos resultados dos modelos de circulação, bem como dos problemas relativos à diferença de escalas, apresentados por Koutsoyiannis et al. (2008) e já citados anteriormente.

Uma limitação da análise realizada é considerar apenas as variaçôes preditas para duas variáveis meterológicas, a temperatura e a precipitação. A velocidade do vento ou a radiação solar, por exemplo, têm uma influência importante sobre as taxas de evapotranspiração, porém sua variação no futuro é de difícil predição.

\section{Referências}

Hulme, M., Wigley, T.M.L., Barrow, E.M., Raper, S.C.B., Centella, A., Smith, S.J. and Chipanshi, A.C. (2000): Using a Climate Scenario Generator for Vulnerability and Adaptation Assessments: MAGICC and SCENGEN Version 2.4 Workbook. Climatic Research Unit, Norwich UK, 52 pp. Berlato, M. Fontana. D (2003): El Niño e La Niña. Editora da UFRGS, 110p.

Koutsoyiannis, D.; Efstratiadis, A.; Mamassis, N.; Christofides, A. (2008): On the credibility of climate predictions. Hydrological Sciences 53(4), 671-684.

Meehl, G.; Covey, C.; Delworth, T.; Latif, M.; McAvaney, B.; Mitchell, J.; Stouffer, R.; Taylor, K. (2007): The WCRP CMIP3 Multimodel Dataset: A New Era in Climate Change. Research. Bulletin of the American Meteorological Society, vol. 88, Issue 9, 1383-1394.

Louzada, A. (2004): Simulação da irrigação por inundação e da drenagem nos solos de várzea do Rio Grande do Sul. Tese de doutorado, IPH-UFRGS, 190p.

Martorano, L. (2007): Padrões de resposta da soja a condições hídricas do sistema solo-planta-atmosfera, observados no campo e simulados no sistema de suporte à decisão DSSAT. Tese de Doutorado, Escola de Agronomia, UFRGS, 151p.

Dalmago, G. A. (2004): Dinâmica da água no solo em cultivos de milho sob plantio direto e preparo convencional. Tese de Doutorado, Escola de Agronomia, UFRGS, 245p.

Sartori, A., Lombardi Neto, F., Genovez, A.M (2005): Classificação Hidrológica de Solos Brasileiros para a Estimativa da Chuva Excedente com o Método do Serviço de Conservação do Solo dos Estados Unidos Parte 1: Classificação. Revista Brasileira de Recursos Hídricos, vol. 10, n 4 p. 5-18.

Manfron, P.A; Bacchi, O; Dourado Neto, D; Pereira, A. R., Medeiros S; Pilau, F. Modelo da Profundidade efetiva do sistema radicular na cultura de milho em função de graus-dia acumulados. Revista Brasileira de Agrometeorologia, SANTA MARIA, v. 11, n. 2, p. 327-332, 2003.

Guerra, A. F e Jacomazzi, M. A Método do tanque classe A para irrigação suplementar da cultura do milho no cerrado. Comunicado Técnico $n^{0} 59$, Embrapa, Brasília.

Collischonn, W (2001): Simulação hidrológica de grandes bacias. Tese de doutorado, IPH-UFRGS, 196p.

Potential impact of climate change over water needs for corn crop irrigation in southern Brazil

Bruno Collischonn Instituto de Pesquisas Hidráulicas /UFRGS. Agência Nacional de Águas. E-mail: bruno.collischonn@ana.gov.br.

José Antônio Louzada Instituto de Pesquisas Hidráulicas/UFRGS. E-mail: louzada@iph.ufrgs.br. 